DOI: http://dx.doi.org/10.4314/star.v4i2.32 ISSN: 2226-7522(Print) and 2305-3372 (Online) Science, Technology and Arts Research Journal Sci. Technol. Arts Res. J., April-June 2015, 4(2): 236-240 Journal Homepage: http://www.starjournal.org/

Original Research

\title{
Design and Simulation of Microcontroller-based Automated Car Parking System
}

\author{
Taye Girma*
}

Department of Computer Science, St. Mary's University, Post Box 120611, Addis Ababa, Ethiopia

\begin{tabular}{|c|c|}
\hline Abstract & Article Information \\
\hline \multirow{4}{*}{$\begin{array}{l}\text { There is a crucial need for managing the parking space in big companies, hotels, market } \\
\text { places, apartments and etc. This is due to an increase in growth rate of the population in the } \\
\text { entire world, which actually leads to the rapid increase in the number of cars being used. } \\
\text { However, the availability of parking space is getting limited as most of the land is used for } \\
\text { multi-purpose buildings. Therefore, the aim of this paper is to design and implement the } \\
\text { microcontroller based automated car parking system with the existing limited parking space. } \\
\text { The automated parking system will make sure the availability of Parking space and, if } \\
\text { confirmed through seven segment displays, the microcontroller will send a command to the } \\
\text { gate to be opened so that the car will be allowed entry into the parking space to park at the } \\
\text { designated slot. Thereafter, the gate will be closed and the updated number of free parking } \\
\text { space will be displayed on the seven segment display. The microcontroller based automated } \\
\text { car parking system was designed to test the system through simulation, The system was } \\
\text { tested using simulation for its correctness to manage a parking slot that can accommodate } \\
99 \text { cars and it was working properly. } \\
\text { Copyright@2015 STAR Journal, Wollega University. All Rights Reserved. }\end{array}$} & $\begin{array}{l}\text { Article History: } \\
\text { Received }: 12-03-2015 \\
\text { Revised }: 30-05-2015 \\
\text { Accepted }: 05-06-2015\end{array}$ \\
\hline & $\begin{array}{l}\text { Keywords: } \\
\text { Microcontroller } \\
\text { Automated Car Parking } \\
\text { Parking Space } \\
\text { Gate } \\
\end{array}$ \\
\hline & $\begin{array}{l}\text { *Corresponding Author: } \\
\text { Taye Girma }\end{array}$ \\
\hline & \\
\hline
\end{tabular}

\section{INTRODUCTION}

In highly populated cities the availability of free parking spots is increasingly becoming scarce. In addition to the rush hour traffic, multiple drivers are observed competing for the same space which actually became a cause for many accidents in parking areas (Tariq, 2009; Bonde et al., 2014). Another challenge is that parking spaces are tight and difficult to maneuver into (Tariq, 2009). With increasing number of automobiles in the recent days and lack of free parking space, especially in metros, hotels, commercial buildings and big companies, the need for developing an automated car parking system which makes efficient use of space and avoids traffic congestion arises (Sumathi et al., 2013; Hitesh J. Lad, 2013).

In the light of the above, this paper deals with a design, simulation and implementation of an automated Car Parking System which can detect available free parking space and then opens an entrance gate for the driver to park at the space with minimum effort (Figure 1).

The growing number of vehicles in the entire world results in the shortage of parking space and totally unregulated parking of vehicles all over. In densely populated areas these are a real challenge for city planners, architects and developers. The need to offer sufficient parking spaces is a task for the respective stakeholder. This situation calls for the need of an automated car parking system which is not only regulating parking in a given area but also keeps the manual control to a minimum. Automated car parking systems is the sole solution to park as many cars as possible in a little space (Sumathi et al., 2013).

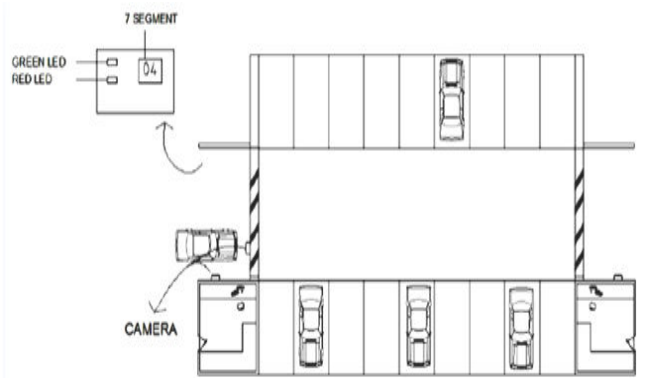

Figure 1: Car Parking System (Md.Towhid Chowdhury and Ebad Zahir, 2013).

The automated parking system is a method of using sequence detecting devices and sensor devices for entering and exiting cars at the Entry and Exit Gate. The entry and exit of cars is made possible using an automated gate (Entry and Exit Gate) connected to sensors. The signals that we get from the sensors indicate whether a car is currently in the process of entering or leaving the parking space and this process is displayed using seven segment LED display. After the initial installation, the system requires no manual control to let the cars leave and enter the parking space. It requires no attendants and is the most cost-effective than conventional parking space where there is no such a system, and allows more cars to be parked in less space. 
The conventional manual parking system do have a problem of unsafe parking, difficulty for checking the available parking lots - that is, unable to control and monitor the number of cars inside the parking area. Additionally, the traditional or manual parking system is prone to accidents and parking jam. A recent survey shows that searching for parking spaces has generated traffic that reach up to $40 \%$ of the total traffic (Hongwei Wang and Wenbo He, 2011).

According to Sumathi et al., (2013), automated car parking system was mainly driven by a need for parking spaces and a scarcity of available land. With the emerging problem of parking cars, the ordinary parking system which does not provide any information about vacant parking areas would not be able to handle the problem effectively. These systems would get the drivers to search the parking areas on their own and thus create a problem where there would be too many cars in the car parking area (Bonde et al., 2014).

However, an automated car parking system enables to count the maximum parking lots i.e., counting the number of cars entering in to (increment number of parked cars and decrement free available space) and exiting (decrement number of parked cars and increment free available space) from the parking lot.

\section{MATERIALS AND METHODS}

\section{Materials}

To build a microcontroller-based automated car parking system, the following hardware and software resources are required:

\section{Hardware Requirements:}

P87C51RD+ Microcontroller: It is the heart of the system that mainly controls other devices to check for the entry and exit of cars. It continuously polls the pins from where we receive the signal from the sensor. When it detects the car from the entry gate then it checks whether there is any available parking space in the parking lot. If there is free space then it opens the entry gate and increases the overall number of parked cars in the parking lot by one and reduces the number of available free space by one, and after 3 seconds the door will be automatically gets closed. However, if it detects the car from the exit gates then it decreases the number of parked cars by one and increases the available free space by one.

ULN2003: used when driving a wide range of loads and as relay drivers, display drivers, line drivers etc., ULN2003 is also commonly used while driving Stepper Motors.

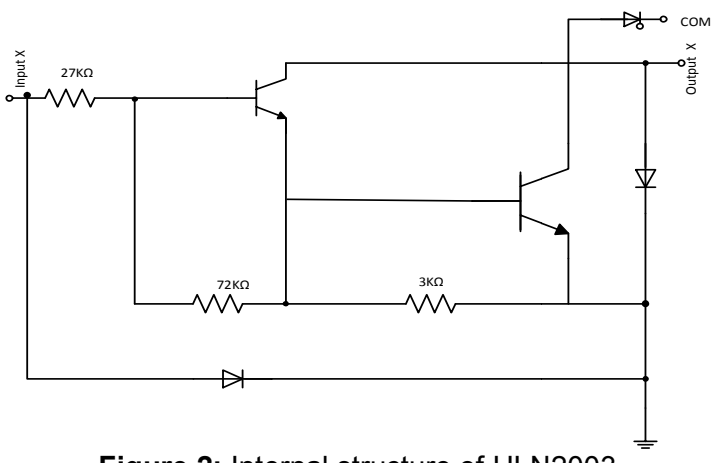

Figure 2: Internal structure of ULN2003
IC 74LS47: It is a BCD to 7-segment decoder. It accepts a binary coded decimal as input and converts it into a pattern to drive a seven-segment for displaying digits 0 to 9. Binary coded decimal (BCD) is an encoding in which each digit of a number is represented by its own binary sequence (usually of four bits).

Stepper Motor: It is a "digital" version of the electric motor. The rotor moves in discrete steps as commanded, rather than rotating continuously like a conventional motor. When stopped but energized, a stepper (short for stepper motor) holds its load steady with a holding torque. Wide spread acceptance of the stepper motor within the last two decades was driven by the ascendancy of digital electronics. Modern solid state driver electronics was a key to its success. And, microprocessors readily interface to stepper motor driver circuits.

Common Anode 7 Segment LED Display: The common cathode has all the cathodes of the 7-segments connected directly together and the common anode has all the anodes of the 7-segments connected together. Shown below is a common anode seven segment used in this paper.

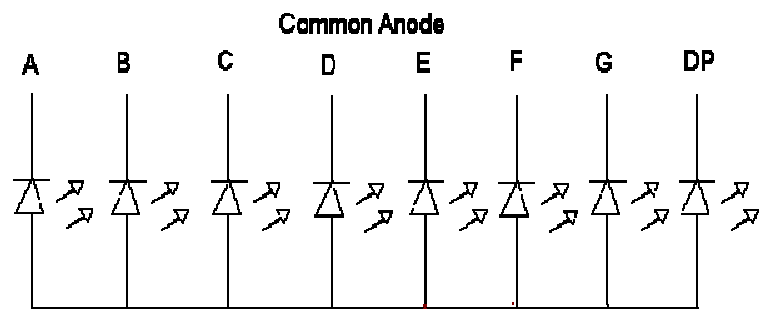

Figure 3: Common Anode 7 Segment LED Disply

As shown above, all the anode segments are connected together and when working with a CA seven segment display, power must be applied externally to the anode connection that is common to all the segments. Then by applying a ground to a particular segment connection (A-G), the appropriate segment will light up. However, an additional resistor must be added to the circuit to limit the amount of current flowing through each LED segment.

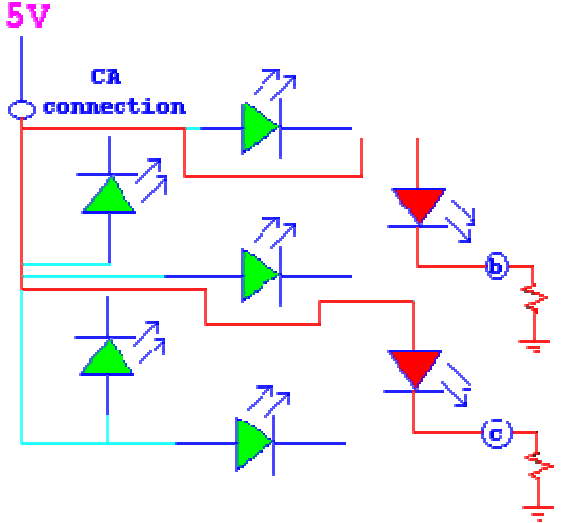

Figure 4: Resistors to limit current flow in each LED

Figure 4 shows the instance when power is applied to the CA connection and segments $b$ and $c$ are grounded causing these two segments to light up.

- Infrared Sensor: It senses the cars coming to the entry gate for parking and it is the sensor that helps the controller to open (Entry Gate) and close (Exit Gate). There will be two infrared sensors, one at Entry Gate and one at Exit Gate. 
- Switch (Push Button): The push button is a component that connects two points in a circuit when it is pressed. That means, when the button is pressed, it turns ON a LED and displays the number of available free space for parking.

- Power supply: is designed to convert high voltage AC main to a suitable low voltage supply for electronic circuits and other devices. A power supply can be divided into a series of blocks (Transformer, Rectifier, smoothing and regulator), each of which executes a specific function.

Transformer steps down high voltage AC mains to low voltage $A C$. Rectifier converts $A C$ to $D C$, but the $D C$ output is varying. Smoothing - smoothes the DC from varying greatly to a small ripple.

\section{Software Requirements}

The built-in ROM size of most microcontroller family that stores the program is very small or limited and hence the program to be written to drive the microcontroller must be efficient in memory requirement. The appropriate programming language that supports less memory requirement with efficient code is assembly language programming. Therefore, this paper used microcontroller based assembly language programming to implement the system.

\section{Methods}

The following design methodology and procedures are used to design, simulate and implement microcontrollerbased automated car parking system:

- Identifying the appropriate microcontroller to use;

- Identifying the appropriate peripheral devices that can be used with selected microcontroller;

- Deciding the number of each peripheral devices that will be used in the system design;

- Identifying and deciding which programming language to use ( $\mathrm{C}$ or Assembly);

- Identifying the simulation environment for the selected microcontroller;

- Design the overall microcontroller-based car parking system;

- Develop the flow chart that can illustrate the operation of the designed systems;

- Write the program using selected programming language that runs the designed system;

- Perform the simulation and test the system for appropriate performance and correctness.

\section{Design and Simulation of Automated Car Parking System}

A designed system has a gate that is provided at the entry of the parking area, which will be opened on the arrival or departure of a car. A display section has been included to show the number of available free car parking spaces in the parking space at any point of time. After the maximum numbers of cars have entered the parking space, the gate is automatically disabled for vehicles seeking entry into the parking lot. The infrared sensor included in the design is used to sense the four wheel cars and that will exclude the people and two wheelers during counting the number of parking to display the available free spaces. The automated car parking circuit primarily uses one P87C51RD+ Microcontroller, infrared sensor for transmission (TX) and receiving (RX) signals, two Seven Segment LED's to display the available free spaces, three decoders : 74LS47 (2) and ULN2003A, one stepper motor for gate control, and two resistor packs for voltage drops (Figure 5).

\section{System Flow Chart}

The following diagram shows the flow chart of the microcontroller-based automated car parking system to show the availability of free parking space. The equivalent assembly code is written to run the entire system so that the available free spaces are indicated to the drivers before trying to get in to the gate (Figure 6).

\section{Pseudo and Microcontroller Based Assembly Code}

Before writing the actual program, the pseudo code that will be converted to equivalent assembly language program to drive the microcontroller is given as follows:

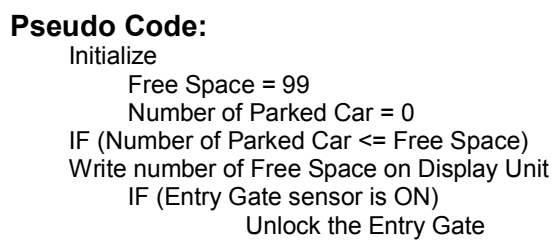

Number of parked car ++

Free Space --

$$
\begin{aligned}
& \text { Lock the Entry Gate } \\
& \text { ELSE (Exit Gate Sensor is ON) }
\end{aligned}
$$$$
\text { Unlock the Exit Gate }
$$

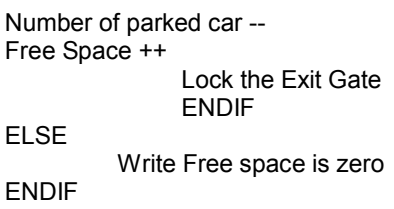

Write Free space is zero

Equivalent Assembly Code for the above Flow Chart ORG 0000

MOV A, \#00110011B

MOV R1, \#11001100B

MOV A, \#99H

MINUS:

MOV P2, \#99H

JB P3.4, PLUS

MOV P1, R1

MOV P1, RO

$D A A$

MOV P2, A

$A D D \quad A, \# 98 H$

$D A A$

CALL DELAY

ADD A, \#1

DJNZ R2, MINUS

CLR P3, 7

MOV P1,R1

$M O V P 1, R O$

CALL DELAY

JMP \$

PLUS:

JB P3.5, MINUS

MOV P1, R1

MOV P1, RO

$A D D A, \# 1 H$

$D A A$

MOV P2, A

CALL DELAY

CJNE A, \#100H, PLUS

DELAY

$J M P \$$

$\begin{array}{ll}\text { DL2: } & \text { MOVR5, \#2 } \\ \text { DL1: } & \text { MOVR6, \#200 } \\ & \text { MOV R7, \#249 } \\ & \text { DJNZ R7, \$ } \\ & \text { DJNZ R6, DL1 } \\ & \text { DJNZ R5, DL2 } \\ & \text { RET }\end{array}$

END 


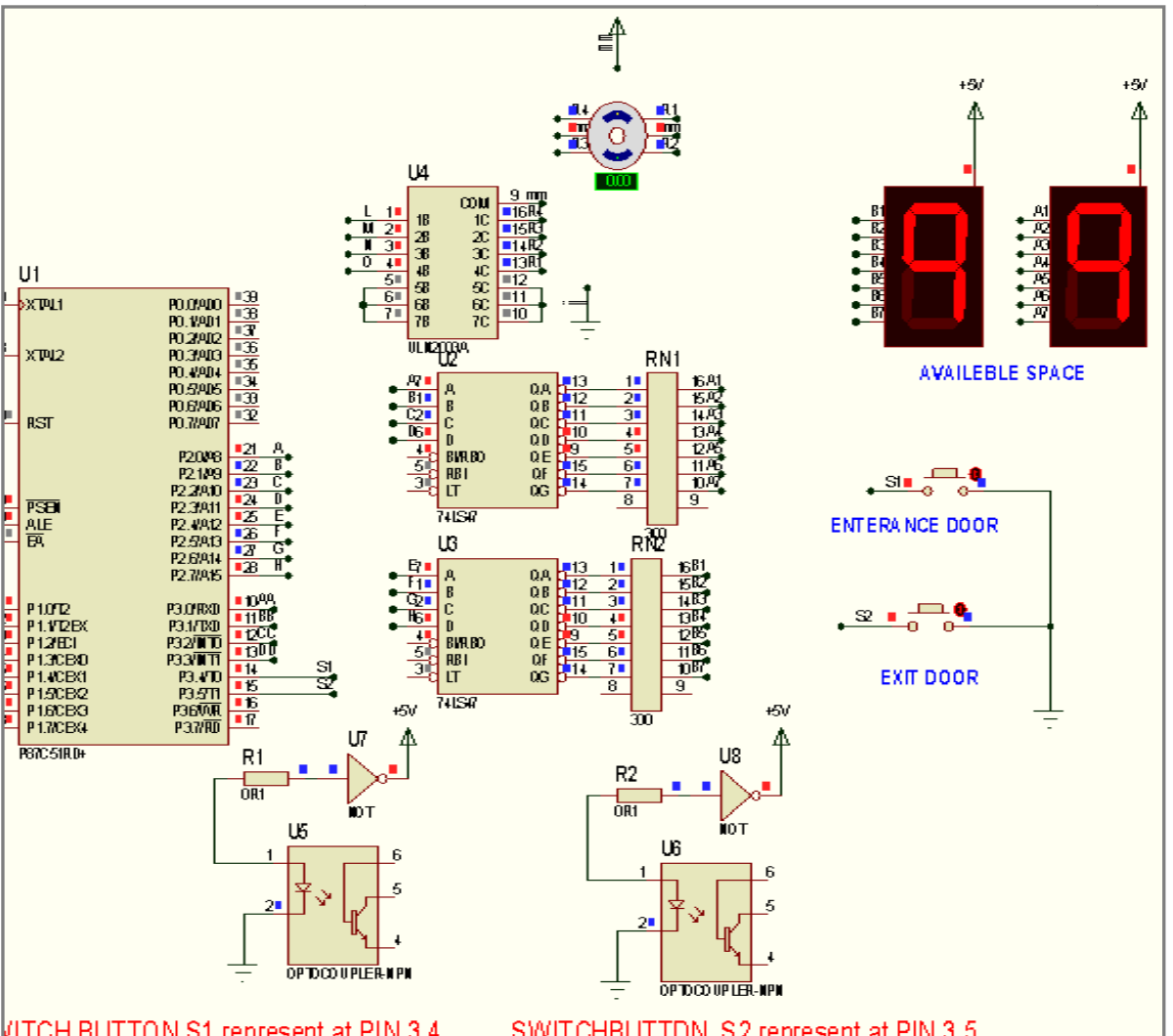

IITCH BUTTON S1 represent at PIN 3.4 SWITCHBUTTDN S2 represent at PIN 3.5

Figure 5: Microcontroller-based automated car parking system

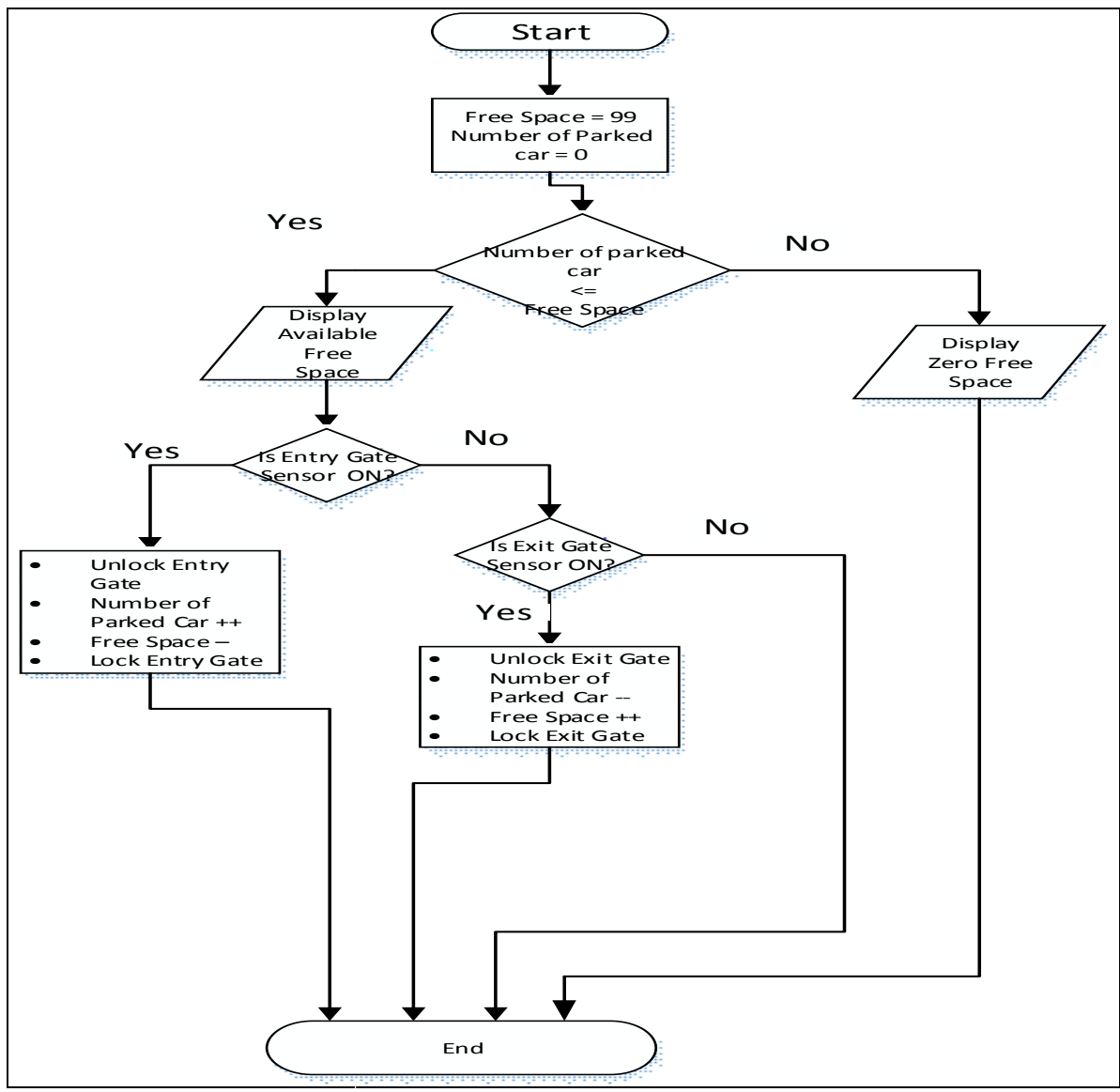

Figure 6: Flowchart diagram for car parking system 


\section{RESULTS AND DISCUSSION}

The microcontroller based automated car parking system was designed to test the system through simulation using one P87C51RD+ Microcontroller, infrared sensor for TX and RX signals, two LED's to display the available free spaces, three 74LS47 (2) and ULN2003A, one stepper motor for gate control, and two resistor packs for voltage drops. The system was tested using simulation for its correctness to manage a parking slot that can accommodate 99 cars and it was working properly. Figure 5 shows the designed microcontroller based automated car parking system. As it is shown on the LED, the first simulation result using Proteus version 7.2 shows that 99 and just below the two LEDs the text message 'AVAILABLE SPACE' is displayed.

This means there are 99 free parking slots which is true. And then the system was tested by increasing the number of entered car using the 'switch button' at the ENTRANCE DOOR. This time the LED displays 98, 97, 96 and goes on, after every press made on switch button at ENTRANCE DOOR. The same testing was again made by decreasing the number of exit cars using the 'switch button' at the EXIT DOOR.

\section{CONCLUSIONS}

This paper presented a simple microcontroller based automated car parking system in which the system tracks and display the free available parking slot. This paper dealt with building a system which is useful for managing available free parking space whether in underground or open space of big companies, hotels, market places and apartments intending to use up to 99 cars. This system can be applied in different areas like parking lots of offices, malls, toll plazas, underground parking areas in metros and commercial buildings (Baglane et al., 2014). This microcontroller-based system reduces unregulated parking system and high traffic jam in parking area. However, the modifications can be made to work on increasing or decreasing the number of cars that the system would count based on additional user requirements. The system can be enhanced to handle cars more than 99 cars by increasing the number of seven segment display and the message can be posted in local languages. In the future, the car parking system can also measure the distance between the cars to increase the efficiency of land use during parking. Moreover, wireless Sensor Networks can also be implemented to sense and disseminate information from various locations or areas with the potential to serve drivers easily identify the number of free available parking spaces.

\section{Conflict of Interest}

Author declared no conflict of interest.

\section{REFERENCES}

Baglane, S.B., Kulkarni, M.S. Raut, S.S., Khatavkar, T.S. (2014). Parking Management System. International Journal of Modern Engineering Research 4(2): 72-77.

Bonde, D. J., Rohit S. Shende., Ketan S. Gaikwad., Akshay S. Kedari., Amol U. Bhokre (2014). Automated Car Parking System Commanded by Android Application International Journal of Computer Science and Information Technologies 5(3): 3001-3004

Edu Twin (2011). [Available online: http://edutwin.com/tAutomatic-car-parking-indicator using-Microcontroller verified 13 May 2015]

Hitesh J. Lad, Vibhuti G. Joshi (2013). Vehicle Parking Management Using Embedded System, International Journal of Engineering Science and Innovative Technology 2(4): 521-527.

Hongwei Wang and Wenbo He (2011). A Reservation-based Smart Parking System. The First International Workshop on Cyber-Physical Networking Systems 1(1):701-706

Md.Towhid Chowdhury and Ebad Zahir (2013). Automotive Parking Lot and Theft Detection through Image Processing. American Journal of Engineering Research 2(10): 308-313.

Sumathi, V., Pradeep Varma, N.V. and Sasank, M. (2013). Energy efficient automated Car parking system. International Journal of Engineering and Technology 5(3): 2848-2852.

Tariq Jamil (2009). Design and Implementation of a Parking Helper. Proceedings of the World Congress on Engineering and Computer Science 1:pp.. 